\title{
Motor Control and Learning Skills According to Cognitive and Ecological Dynamic Approach in a Vision on Behaviorism, Cognitive, Gestalt and Phenomenology Theories
}

\author{
Gaetano Raiola \\ University of Parthenope Naples, Italy \\ Email: raiolagaetano@libero.it
}

Doi:10.5901/mjss.2014.v5n15p504

\begin{abstract}
In physical activity and sport, teaching method is traditionally imparted by the coach or teacher with tutorials that have the theoretical basis in the Cognitive approach. It means, they illustrate greatly and the tutorials are of Partial type, Varied one, Randomized one, Mental Training one and, finally, using the feedback for error correction. Cognitive approach has the physiological and psychological basis in theory of motor control in Circuit Open Loop, Circuit Closed Loop and Motor Program Generalized. Otherwise, teaching methods of physical activity and sport could be suggested in another way, called EcologicalDynamic approach, where the dynamic is opposite in the past case. The coach or the teacher does not use the tutorials, but he uses to build a setting learning aimed at variety of motor skills and he plays of the phenomenon in a natural way using the variables. This second approach has the physiological and psychological basis in theory of motor control in Motor Imagery and Freedom Degrees. The Motor Imagery could be made in first person and in third person. Freedom Degrees is made by three consecutive steps: Reduction of Freedom Degrees, Exploration of new Freedom Degrees and Capitalization of the final Freedom Degrees. Behaviorism and Cognitive theory have the mind in the focus of learning process. Vice versa, Gestalt and Phenomenology has the environment in the focus of learning process. Both of them has the main difference between the role of the mind and the role of the learning setting. Aim is to study the issue of motor control theory and what is the correlation to learning process and motor skills. Specifically, to aim the relation on mind theory such as the fourth principal of them. Methods of this study is to analyze the specific aspects of learning approach in physical activity and sport. After, to analyze the elements of mind theory according to Behaviorism, Cognitive, Gestalt and Phenomenology and then to elaborate the logical relation. Main results and conclusion show two types of relationship. The first one is between cognitive approach, which includes closed loop motor control, open loop motor control and generalized motor program, with Behaviorism and Cognitive. Furthermore, there is a significant relationship among tutorials techniques such as order, demand, sequence and timing and the prescriptive teaching method of Behaviorism and Cognitive applied to motor skill. The second one is between ecological dynamic approach, which includes Motor Imagery and Freedom Degrees, and Gestalt and Phenomenology. Furthermore, there is a significant relationship among learning setting, such as environment and specific strategies of teaching method, and the strategies of cooperative learning, role playing, circle time, brain storming, peer education, tutorship, focus group. So it can observe the invasive role of the coach or the teacher in cognitive approach and non-invasive role in ecological dynamic approach. In conclusion, it suggests to deep the ideal setting in educational process in school and in sport association.
\end{abstract}

Keywords: Cognitive, Closed loop, Open loop, Generalized motor program, Ecological-Dynamic, Motor imagery, Freedom degrees

\section{Introduction}

In physical activity and sport, teaching method is traditionally imparted by the coach or teacher with tutorials that have the theoretical basis in the Cognitive approach. It means, he greatly illustrates the tutorials, that are of Partial type, Varied one, Randomized one, Mental Training one and, finally, by using the feedback for error correction. Cognitive approach has the physiological and psychological basis in theory of motor control in Circuit Open Loop (Schimdt 1975), Circuit Closed Loop (Adams, 1968, 1971) and Motor Program Generalized (Schimdt, Wrisberg, 2004). Teaching Methods of physical activity could be suggested the motor skills in another way, called Ecological-Dynamic approach (Carnus, Marsualt 2003). In this case, the coach or the teacher does not use the tutorials, but they uses to build a setting learning aimed at variety of skills and they play in the variables of the phenomenon. This second approach has the physiological (Edelman, 1987) and psychological basis in theory of motor control in Motor Imagery (Jeannerod, 2002ab, 2006) and Freedom Degrees (Bernstein, 1991). The first one could be made in first person and in third person; the second one is made by three consecutive steps: Reduction of Freedom Degrees, Exploration of new Freedom Degrees and Capitalization of the final Freedom Degrees. It analyses the current state of the affair of how and why the body and movement are central in the motor skills, through methodological and teaching method choices in teaching activities at 
whose foundation there is scientific evidence. "Conceptual knowledge is embodied, that is mapped in our sensory-motor system. This not just provides the structure to the conceptual content, but characterizes the semantic content of concepts according to the way we function in the world with our bodies." (Gallese \& Lakoff, 2005). Teaching method of cognitive approach is, traditionally, made by using tutorials. Sport and physical activity is traditionally imparted by the coach or the teacher in illustration and simulation actions in details. They are: Partial type, Varied one, Randomized one, Mental Training and Feedback by correction of the error. They refer to the motor control models of Open Loop, Closed Loop, and Motor Program Generalized. The partial tutorial consists in making exercise a complex motor skill initially in a simplified form. Movements, with a great level of difficulty and the high degrees of complexity, can be simplified by dividing the exercises in little part or reducing the speed or requests for precision. In other words, the coach or the teach use in varied forms the space and the time. For all forms of partial tutorial is the rule that is obtained of learning only as long as the techniques of partial tutorial, that is fragmentation, segmentation and simplification, does not adversely affect the deep structure of the motor program generalized. The tutorial randomized and that varied are other techniques of tutorial that find their justification in theory engine programs generalized. The theory of the programs motors has generalized methodological implications-didactic on direct choice of which provide information in the feedback. This choice depends on the type of error made by the athlete/student. The techniques of mental repetition consist in think about the aspects cognitive and procedural of the action, while the mental representation is to imagine the conduct of an action. Despite, the Ecological-Dynamic approach, where the coach does not require the tutorials but builds a setting learning environment, aims at variety of learning. It refers to the models for the control of the imagination and mobility of the theory of the degrees of freedom in three consecutive steps for learning impairment: Reduction, Exploration and Capitalisation of the degrees of freedom (Latash, 2004). According to the ecological approach "learn" means being able to find progressively the mobility solution best for a given task in a given context. Emblematic is the expression, coined by Bernstein, "repetition. without repetition": practice does not mean always repeat the same solution to a given task, but repeat over again the process of solving the task itself. If learn movements means optimizing the process of solving tasks engines, resulting didactic implications different from those prescriptive own cognitive approach. In heuristic learning the teacher must assist the student in research autonomous mobility solutions. If the learning tasks too complex, you should not impose constraints to the learner in telling him how prescriptive him how prescriptive simplify the implementation mobility, but you must apply constraints to the environment. Behaviorism and Cognitive theory have the mind in the focus of learning process. Vice versa, Gestalt and Phenomenology has the environment in the focus of learning process. Both of them has the main difference between the role of the mind and the role of the learning setting. Aim is to study the issue of body knowledge by motor control theory and its relation to motor skills. To study deeply the issue of motor control theory and what is the correlation to learning process and motor skills. Specifically, to aim the relation on mind theory such as the fourth principal of them.

\section{Methods}

Methods of this study is theoretical and argumentative by deductive way (Di Tore, Raiola, 2012abc). To analyze the specific aspects of learning approach in physical activity and sport. After, to analyze the elements of mind theory according to Behaviorism, Cognitive, Gestalt in Gibson (1979) vision and Phenomenology theory and then to elaborate the logical relation to cognitive and ecological-dynamic approach. It uses an integrated method that joins, in one hand, the elaborations of specific aspects, by documentary approach that describes the evolution steps, particularly on theoretical paradigms on teaching methods about motor skills. In other hand, it uses an argumentative approach by deductive way to talk about on new discoveries on motor control and learning.

\section{Results and Conclusion}

It shows two types of relationship: first one is between cognitive approach, which includes closed loop motor control, open loop motor control and generalized motor program, and Behaviorism and Cognitive. Furthermore, there is a significant relationship among tutorials techniques such as order, demand, sequence and timing and the prescriptive teaching method of Behaviorism and Cognitive theory on applied movement learning. The second one is between ecological dynamic approach, which includes Motor Imagery control and Freedom Degrees control. Furthermore, there is a significant relationship among learning setting, such as learning environment and specific strategies of teaching method and the strategies of cooperative learning, role playing, circle time, brain storming, peer education, tutorship, focus group. In conclusion it can observe the invasive role of the coach or the teacher in cognitive approach and non-invasive role in ecological dynamic approach. Cognitive approach is an usual way to understand the movement, that is the historical way 
to study and investigate the issue in behaviorist/cognitive interpretative key. Ecological Dynamic approach is an extraordinary way to understand the movement, that is the innovation way to study and investigate the issue in gestalt/phenomenology interpretative key in a new vision on mirror neurons (Rizzolatti, 2006). In conclusion, it suggests to deep the ideal setting in educational process in school and in sport association (Raiola 2012).

\section{References}

Adams, J.A. (1968). Response feedback and learning. "Psychological Bulletin", 70, 486-504. teaching relevance and availability of Anochin's theoretical model Sport Science Vol. 4, Issue 2

Adams J.A. (1971) A closed-loop theory of motor learning. Journal of Motor. Behavior, 3:111-15

Bernstein, N.A (1991) On co-ordination and its development, Moskow: University press

Carnus, S, \&Marsualt C. (2003) Repenser l'EPS à partir de l'approche ecologique - Rivista EPS, édition revue EPS - Nº 302 pag. 13, Paris

Edelman G M, (1987) Neural Darwinism. The theory of Neuronal group Selection, Basic Books, New York.,

Di Tore P A, Raiola G (2012a). Case study on Physical Education and Sport in Naples. Mediterranean Journal of Social Sciences, vol. 3 , p.479-484, doi 105901/mjss 2012.v3n1p.479

Di Tore P A, Raiola G (2012b). Exergames and motor Activities Teaching : An Overwiev of Scientific Paradigm of Motor Control, Mediterranean Journal of Social Sciences, vol. 3, p. 119-122 doi 105901/mjss 2012.v3n1p.119

Di Tore P A, Raiola G (2012c). Non-verbal communication and volleyball: A new way to Approach the phenomenon, Mediterranean Journal of Social Sciences, vol. 3, p. 347-356 doi 105901/mjss 2012.v3n2p.347

Gallese, V, \& Lakoff, G. (2005) The Brain's concepts: the role of the Sensory-motor system in conceptual knowledge. Cognitive Neuropsychology, 22(3/4), 455-479

Gibson J.J. (1979) The Ecological Approach to Visual Perception. Boston: Houghton Mifflin

Jeannerod, M. (2006). Motor cognition: What actions tell the Self. Oxford University Press

Jeannerod, M. (2002a). Le Cerveau intime. Paris: Editions Odile Jacob

Jeannerod, M. (2002b). La Nature de l'esprit. Paris: Editions Odile Jacob

Latash, Mark L. (2004) Progress in Motor Control: Bernstein's Traditions in Movement Studies, Vol. 1 Human Kinetics USA

Raiola G (2012). Bodily Communication in Volleyball Between Human and Experimental Sciences. Mediterranean Journal of Social Sciences, vol. 3, p.587-597, doi 105901/mjss 2012.03.01.603

Rizzolatti G, (2006), So quel che fai. II cervello che agisce e i neuroni specchio, Raffaello Cortina Editore, Milano

Schmidt, Richard A. (1975). A schema theory of discrete motor skill learning. Psychological Review 82 (4): 225260. doi:10.1037/h0076770

Schimdt R, Wrisberg D, (2004) Motor Learning and Performance, Human Kinetics USA 